\title{
Epidemiology of Confirmed COVID-19 Deaths in Adults, England, March-December 2020
}

Alison E. Brown, Ellen Heinsbroek, Meaghan M. Kall, Hester Allen, Kazim Beebeejaun, Paula Blomquist, Ines Campos-Matos, Colin N.J. Campbell, Hamish Mohammed, Katy Sinka, Theresa Lamagni, Nicholas Phin, the PHE COVID-19 Mortality Working Group, ${ }^{1}$ Gavin Dabrera

Of the 58,186 coronavirus deaths among adults in England during March-December 2020, $77 \%$ occurred in hospitals, $93 \%$ were in patients $\geq 60$ years, and $91 \%$ occurred within 28 days of positive specimen. Cumulative mortality rates were highest among persons of Black, Asian, other, or mixed ethnicities and in socioeconomically deprived areas.

$\mathrm{R}$ eliable ascertainment and description of mortality rates is vital in monitoring the public health response to coronavirus disease (COVID-19). Disparities between population subgroups provide critical insights into which groups are most affected, directly informing the public response. In England, COVID-19 was first detected on January 30, 2020; the first COVID-19 death occurred on March 2, 2020. We describe trends in COVID-19 mortality rates by age group, sex, ethnicity, residential region and socioeconomic deprivation, time from positive specimen date to death, and place of death during the first 9 months after the first known COVID-19 death in England.

\section{The Study}

Public Health England (PHE) receives daily reports of the date of death, the date the specimen is taken for COVID-19 testing, and laboratory results for adults $\geq 18$ years of age from 3 sources: hospital trusts using the COVID-19 Patient Notification System; local PHE Health Protection Teams (for nonhospital settings); and the National Health Service Demographic Batch Service, which matches of all laboratory-confirmed COVID-19 cases against registered deaths records. Data from each source were combined daily into a single dataset, the COVID-19 Specific Mortality Surveillance System (COSMOSS) (1).

Author affiliation: Public Health England, London, UK

DOI: https://doi.org/10.3201/eid2705.203524
COSMOSS data are matched using a unique patient identifier (National Health Service number) to death registrations from the Office for National Statistics (2) to ascertain setting and cause of death. The data are then matched to Hospital Episode Statistics to identify ethnicity and to area-level data to categorize relative socioeconomic deprivation based on Indices for Multiple Deprivation (IMD) (3). Data are deduplicated daily so that 1 record reported from the multiple data sources is retained for each decedent.

COSMOSS COVID-19 deaths are defined as any death occurring within 60 days of a date on which a positive specimen was taken for COVID-19, or any death for which COVID-19 is listed on the death registration (codes U0.71 or U0.72 from the International Classification of Diseases, 10th Revision, Clinical Modification) (2). Cumulative mortality rates (deaths/100,000 population) were calculated using denominator data from Office for National Statistics population estimates (4).

By December 3, 2020, a total of 58,186 COVID-19 deaths in adults had been reported to PHE, yielding a crude mortality rate of 132 deaths/100,000 population. An additional 31 deaths among children (persons $<18$ years of age) were reported.

Social distancing measures were announced nationally on March 23, 2020, 3 weeks after the first death. The number of COVID-19 deaths peaked on April 8, $\approx 2$ weeks after social distancing began (Figure 1,2$)$, gradually fell to lower levels that were sustained throughout summer, and then increased in late September.

Overall, 93\% $(54,282)$ of deaths in adults occurred in persons $\geq 60$ years of age, and $57 \%(32,970)$

${ }^{1}$ Members of the PHE COVID-19 Mortality Working Group are listed at the end of this article. 


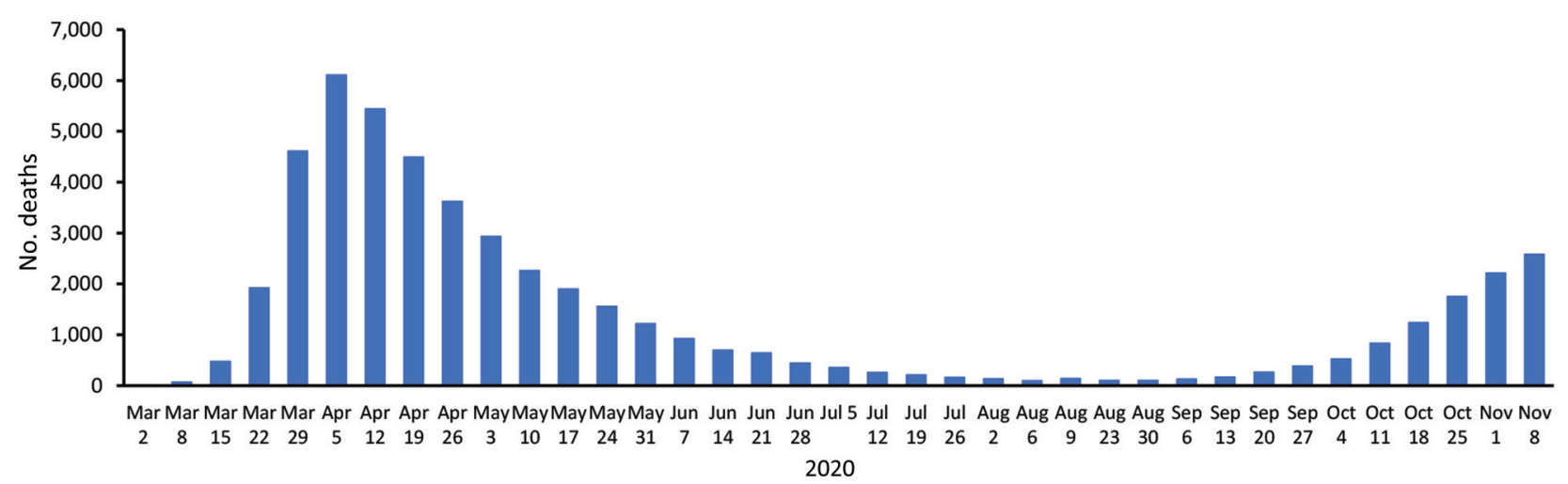

Figure 1. Deaths occurring within 60 days of a laboratory-confirmed coronavirus disease (COVID-19) diagnosis or with COVID-19 on the death registration certificate, by date of death, England, UK, March 2-December 3, 2020.

occurred in men (Table); $64 \%$ of those $18-59$ years of age were men. The cumulative mortality rate was 410 deaths $/ 100,000$ population among persons $\geq 60$ years of age, $>30$ times more than persons $18-59$ years of age (13 deaths/100,000 population) (Table). During March 2-December 3, 2020, a total of $0.50 \%$ of men and $0.34 \%$ of women $>60$ years of age died, compared with $0.02 \%$ of men and $0.01 \%$ of women of working age. Irrespective of age, cumulative mortality was highest in men, Black persons, Asian persons, persons of other or mixed ethnic groups, and persons in socioeconomically deprived areas (Table).

Place of death was available for $86 \%(50,227)$ of decedents. Overall, $77 \%$ of deaths occurred in hospitals, $18 \%$ in residential care homes, and the remainder elsewhere (e.g., home, hospices, and other communal establishments). The median time from specimen date to death was 8 days (interquartile range $4-15$ days); $91 \%(53,000)$ died within 28 days of the specimen date. Of those dying in hospital, $96 \%$ died within 28 days of the specimen date, compared with $86 \%$ in residential care homes and $84 \%$ elsewhere.

When we compared first 4.5 month period with the second, the demographic profile of decedents did not change substantially by sex $(57 \%$ vs. $57 \%$ were men), ethnicity ( $87 \%$ vs. $89 \%$ White), place of death $(77 \%$ vs. $78 \%$ hospital), or time to death $(91 \%$ vs. $91 \%$ within 28 days of specimen date). However, region of death became less London-focused (Figure 2), and the proportion of deaths occurring in the most deprived residential quintile rose from $24 \%$ to $30 \%$.

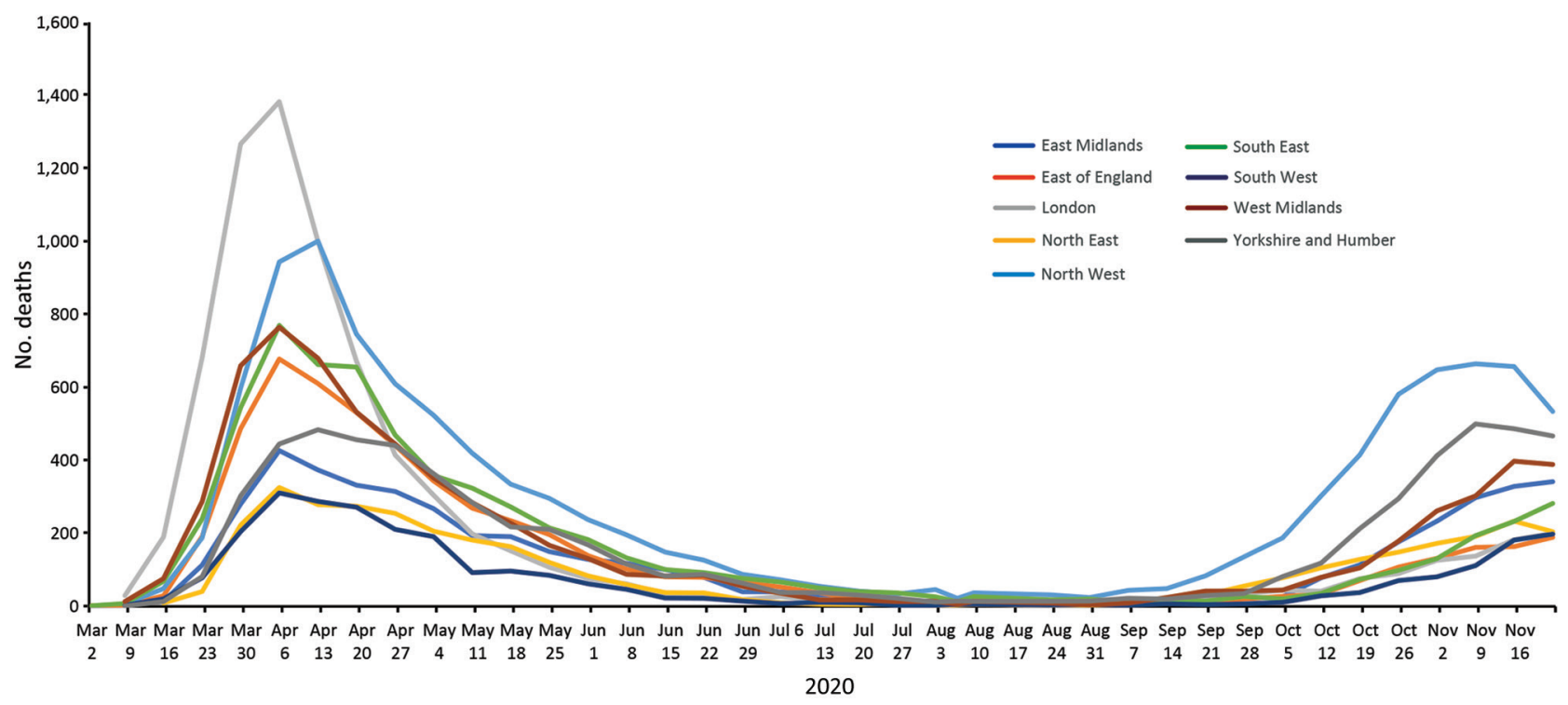

Figure 2. Region-specific coronavirus disease cumulative mortality rate (deaths $/ 100,000$ population), by week of death, England, UK, March 2-December 3, 2020. 
Table. Coronavirus disease cumulative mortality rates among adults, by age group, sex, region, ethnicity, and residence-based socioeconomic deprivation score, England, UK, March 2-December 3, 2020*

\begin{tabular}{|c|c|c|c|c|c|c|}
\hline \multirow[b]{3}{*}{ Characteristic } & \multicolumn{6}{|c|}{ Age group, $y$} \\
\hline & \multicolumn{3}{|c|}{$18-59$} & \multicolumn{3}{|c|}{$\geq 60$} \\
\hline & $\begin{array}{l}\text { No. cumulative } \\
\text { deaths }\end{array}$ & Population $\uparrow$ & $\begin{array}{c}\text { Cumulative } \\
\text { mortality rate§ }\end{array}$ & $\begin{array}{l}\text { No. cumulative } \\
\text { deaths }\end{array}$ & Populationt & $\begin{array}{c}\text { Cumulative } \\
\text { mortality rate§}\end{array}$ \\
\hline \multicolumn{7}{|l|}{ Sex } \\
\hline $\mathrm{F}$ & 1,406 & $15,399,252$ & 9.1 & 23,809 & $7,081,746$ & 336 \\
\hline M & 2,497 & $15,399,681$ & 16.2 & 30,473 & $6,141,881$ & 496 \\
\hline \multicolumn{7}{|l|}{ Region } \\
\hline London & 868 & $5,266,170$ & 16.5 & 6,959 & $1,437,281$ & 484 \\
\hline South East & 368 & $4,554,266$ & 8.1 & 6,399 & $2,217,002$ & 289 \\
\hline East of England & 371 & $3,313,330$ & 11.2 & 5,332 & $1,646,457$ & 324 \\
\hline West Midlands & 479 & $3,059,310$ & 15.7 & 6,696 & $1,405,816$ & 476 \\
\hline Yorkshire and Humber & 399 & $2,854,445$ & 14.0 & 6,494 & $1,324,798$ & 490 \\
\hline East Midlands & 299 & $2,486,593$ & 12.0 & 4,844 & $1,201,199$ & 403 \\
\hline North West & 727 & $3,803,145$ & 19.1 & 10,708 & $1,765,241$ & 607 \\
\hline North East & 182 & $1,377,087$ & 13.2 & 3,652 & 686,963 & 532 \\
\hline South West & 156 & $2,797,918$ & 5.6 & 2,777 & $1,568,870$ & 177 \\
\hline \multicolumn{7}{|l|}{ Ethnicity } \\
\hline White & 2,625 & $25,429,023$ & 10.3 & 48,054 & $12,384,629$ & 388 \\
\hline Black or Black British & 407 & $1,299,892$ & 31.3 & 1,523 & 202,902 & 751 \\
\hline Asian or Asian British & 561 & $2,920,985$ & 19.2 & 3,163 & 510,845 & 619 \\
\hline Mixed & 56 & 750,086 & 7.5 & 241 & 66,357 & 363 \\
\hline Other & 187 & 398,948 & 46.9 & 866 & 58,894 & 1,470 \\
\hline \multicolumn{7}{|l|}{ IMD score } \\
\hline 1 (most deprived) & 1,299 & $6,214,331$ & 20.9 & 13,633 & $1,934,761$ & 705 \\
\hline 2 & 985 & $6,414,752$ & 15.4 & 11,601 & $2,314,652$ & 501 \\
\hline 3 & 651 & $5,925,517$ & 11.0 & 10,226 & $2,777,687$ & 368 \\
\hline 4 & 537 & $5,619,071$ & 9.6 & 9,824 & $2,965,692$ & 331 \\
\hline 5 (least deprived) & 377 & $5,263,233$ & 7.2 & 8,577 & 3020639 & 284 \\
\hline Total $^{*}$ & 3,904 & $30,798,933$ & 12.7 & 54,282 & $13,223,627$ & 410 \\
\hline $\begin{array}{l}\text { "IMD, Indices for Multiple Dep } \\
\text { †Deaths with missing informat } \\
\text { For IMD (3), population denom } \\
\text { §Deaths } / 100,000 \text { population. }\end{array}$ & $\begin{array}{l}\text { cluded: } 476 \text { for } \\
20-59 \text { and } \geq 60\end{array}$ & ט & $\begin{array}{l}\text { and 4h } \\
\mathrm{d} \text { is fro }\end{array}$ & 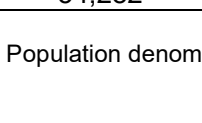 & $1,, L L U, U L r$ & xcept for IMD. \\
\hline
\end{tabular}

\section{Conclusions}

In the 9-month period after the first COVID-19 death in England, $\approx 58,000$ adults died of COVID-19 (5). COVID-19 deaths disproportionately affected specific adults; 9 of 10 occurred among those $\geq 60$ years of age. Men, Black persons, Asian persons, persons of other or mixed ethnic groups, and residents in deprived areas also experienced higher cumulative mortality rates compared with White persons and persons in less deprived areas. Almost 1 of 10 persons died $>28$ days after their specimen date, and 1 of 4 persons died outside hospital.

This comprehensive epidemiologic overview of COVID-19 deaths in England directly informs the pandemic response, including vaccination strategy, and highlights inequalities between populations that require redress $(6,7)$. Previous reports focused on subsets of deaths, primary-care records, or both. However, our results are consistent with other studies in the United Kingdom (A.B. Docherty et al., unpub. data, https:/ / doi.org/10.1101/2020.04.23.20076042; The OpenSAFELY Collaborative et al., unpub. data, https:/ / doi.org/1 $0.1101 / 2020.05 .06 .20092999)$ that show older age is associated with higher COVID-19 mortality rates (8).
The increased rates in older age groups might be attributable to physiologic factors, such as immune senescence (9), which, combined with other factors, can increase the risk for acquiring COVID-19 (e.g., frequently receiving healthcare) and complications (e.g., underlying conditions). The higher mortality rates among Black persons, Asian persons, persons of other or mixed ethnic groups, and persons in more deprived areas are probably influenced by factors that reduce capacity to maintain social distancing, including occupation, use of public transportation, crowded or multigenerational housing, and higher rates of chronic conditions (6).

The cumulative mortality rate of 132 deaths $/ 100,000$ population in our study is consistent with reports from other countries in Western Europe (10). However, meaningful comparisons of COVID-19 mortality rates are limited by differing levels of pandemic activity, definitions for COVID-19 deaths, and methods of reporting.

No international standard exists for defining COVID-19 deaths. Some countries exclude deaths occurring $>28$ days after specimen date; the absence of a time cutoff increases the risk that unrelated deaths are miscoded as COVID-19. Furthermore, daily monitoring 
of deaths within 28 days might be used as a proxy for underlying incidence and a pragmatic alternative to death registrations that can be delayed. However, we estimate that a 28 -day cutoff excludes $\approx 9 \%$ of $\mathrm{CO}$ VID-19 deaths (1). In England, 2 metrics are produced: all deaths within 28 days of specimen date, and all deaths within 60 days of specimen date or with COVID-19 listed on the death certificate (1). These definitions were selected after rigorous sensitivity analyses relating to cause of death (1). A global consensus on defining COVID-19 deaths is needed urgently.

The PHE mortality reporting system (COSMOSS) was developed rapidly, is comprehensive, and captures deaths daily in all settings (1). However, our definition excludes those who died of $\mathrm{CO}$ VID-19 without having a test and for whom no death registration certificate is yet available. This exclusion is likely most relevant at the start of the epidemic, when tests were only undertaken at hospital admission; we estimate $\approx 20 \%$ of deaths occurred outside of hospitals. Finally, increasing evidence indicates that long-term health problems can occur after COVID-19, but the impact on COVID-19 mortality is unknown.

Further analyses using multivariate models are underway and will better measure the clinical and demographic risk factors for COVID-19 deaths. Furthering understanding of the characteristics of those who die and the context in which they are living is the only way we can reduce COVID-19 mortality overall and address the factors that are driving the inequalities observed across England.

PHE COVID-19 mortality working group (in alphabetical order): Hannah Charles, Jayne Evans, Sarah Foulkes, Sema Mandal, Elizabeth Marchant, Olisaeloka Nsonwu, Anne-Marie O'Connell, Rebecca Russell, Ruth Simmons, Julia Stowe, Simon Thelwall, and Kate Twohig.

\section{Acknowledgments}

We thank Myer Glickman and Nalyni Shanmugathasan.

This work was undertaken as a core function of work at Public Health England, and no financial support was provided.

\section{About the Author}

Dr. Brown is an HIV epidemiologist at Public Health England.

\section{References}

1. Public Health England. PHE data series on deaths in people with COVID-19: technical summary - 12 August update [cited 2020 Dec 17]. https:/ / www.gov.uk/government/ publications/phe-data-series-on-deaths-in-people-withcovid-19-technical-summary

2. Office of National Statistics. Deaths involving COVID-19, England and Wales, provisional [cited 2020 Dec 17]. https://www.ons.gov.uk/peoplepopulationandcommunity/ birthsdeathsandmarriages/deaths/datasets/weeklyprovisionalfiguresondeathsregisteredinenglandandwales

3. Ministry of Housing, Communities, and Local Government. English indices of deprivation, 26 September 2019 [cited 2020 Dec 17]. https://www.gov.uk/government/statistics/ english-indices-of-deprivation-2019

4. Office of National Statistics. Population estimates 2018 [cited 2020 Dec 17]. https:/ / www.ons.gov.uk/peoplepopulationandcommunity/populationandmigration/populationestimates

5. Public Health England. Weekly COVID-19 surveillance report published [cited 2020 Dec 17]. https:// assets.publishing.service.gov.uk/government/uploads/system/uploads/ attachment_data/file/901803/Weekly_COVID19_ Surveillance_Report_week_29_FINAL.pdf

6. Public Health England. Beyond the data: understanding the impact of COVID-19 on BAME groups. June 2020 [cited 2020 Dec 17]. https:/ / assets.publishing.service.gov.uk/ government/uploads/system/uploads/attachment_data/ file/892376/COVID_stakeholder_engagement_synthesis_ beyond_the_data.pdf

7. Public Health England. Disparities in the risk and outcomes of COVID-19. June 2020 [cited 2020 Dec 17]. https:/ / assets. publishing.service.gov.uk/government/uploads/system/ uploads/attachment_data/file/892085/disparities_review.pdf

8. Kluge HHP. Older people are at highest risk from COVID-19, but all must act to prevent community spread. April 2, 2020 [cited 2020 Jul 17]. http:/ / www.euro.who.int/en/ health-topics/health-emergencies/coronavirus-covid-19/ statements/statement-older-people-are-at-highest-risk-fromcovid-19,-but-all-must-act-to-prevent-community-spread

9. Koff WC, Williams MA. COVID-19 and immunity in aging populations - a new research agenda. N Engl J Med. 2020;383:804-5. https://doi.org/10.1056/NEJMp2006761

10. European Centre for Disease Prevention and Control. COVID-19 country overviews [cited 2020 Dec 17]. https://covid19-country-overviews.ecdc.europa.eu

Address for correspondence: Dr. Alison Brown, Public Health England, National Infection Service, 61 Colindale Ave, London NW9 5EQ, UK; email: alison.brown@phe.gov.uk 